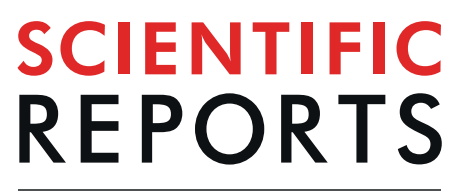

natureresearch

\title{
Effect of bisphenol A on human neutrophils immunophenotype
}

\author{
Wioletta Ratajczak-Wrona ${ }^{1 *}$, Małgorzata Rusak ${ }^{2}$, Karolina Nowak $^{1}$, Milena Dabrowska ${ }^{2}$, \\ Piotr Radziwon ${ }^{3} \&$ Ewa Jablonska ${ }^{1}$
}

Neutrophils (PMN) play a key role in eliciting congenital immune response. These cells are equipped with specific receptors that are located on the surface of their cell membrane. These receptors produce various signals which in turn help in the effective functioning of PMN. The activity of these cells may be modified by factors of endo- and exogenous origin, including xenoestrogens such as bisphenol A (BPA). The aim of this study was to evaluate the effect of BPA on the expression of CD11C, CD14, CD15, CD16, $\mathrm{CD} 62 \mathrm{~L}$ and $\mathrm{CD} 284$ compounds on the surface of neutrophils in women and men. The study material included PMN isolated from the whole blood. The cells were incubated in the presence of BPA and/or LPS. Flow cytometry technique was used to evaluate the expression of $C D$ antigens. Studies of these receptors indicate that BPA, at a concentration corresponding to the serum level of this compound in healthy subjects as well as at higher doses, induces changes in the immunophenotype of PMN, which may lead to immunity disorders associated with the dysfunction of these cells. Moreover, the observed effects of xenoestrogen on the expression of CD11C, CD14, CD15, CD16, CD62L and CD284 differentiation markers on these cells are sex-independent.

There has been an increase in the number of allergic diseases, diabetics, obese individuals, and cases of endocrine, neurological and sexual disorders worldwide since the twentieth century and continues to show an increasing trend. This observation can be attributed to the rapidly growing chemical pollution of the environment. Humans are constantly exposed to natural and synthetic chemical compounds. Among them, xenoestrogens, estrogen-like compounds of exogenous origin endocrine disrupting compounds (EDCs), play an important role. They have the ability to interact with the hormonal system and modulate its functions in a manner that is characteristic for estrogens. Sources of xenoestrogens include some pharmaceutical compounds, metals, detergents, and chemicals used to harden plastics, such as bisphenol A (BPA $)^{1-7}$. The popularity of plastic products has lead to the widespread use of BPA. BPA easily penetrates into food and beverages at elevated temperatures or as a result of damage caused at the time of packaging. Humans are exposed to this compound mainly through food products, and the absorption is found to be particularly high in children. BPA is known to exert harmful effects on human health even at low concentrations. This factor disturbs the hormonal homeostasis of the organism, leading to infertility and cancers ${ }^{4,5,8-10}$.

Bisphenol A can affect the body functions through complex and still not fully understood mechanisms, including both the interaction with receptors and the influence on the permeability of cell membranes. There is evidence to prove that low levels of BPA cause negative effects on the female hormone estrogen, consequently causing a disruption of the hormonal balance in the body. The chemical structure of BPA is similar to that of phenol, thus enabling it to act as an agonist or antagonist. Its action is probably dependent on the content of estrogens $^{1,3,8}$. At lower concentration of estrogens in the body, it exhibits agonist characteristics, while at higher concentrations, it behaves as an antagonist $\mathrm{t}^{1,11}$. BPA can bind to estrogen receptors, estrogen-related receptors, aryl hydrocarbon receptors, and peroxisome proliferator-activated receptors. Owing to its ability to interact with many types of receptors, BPA has a wide impact on immune system regulation ${ }^{12}$.

Despite the conductance of numerous scientific studies on BPA, its effects on PMN are still unclear ${ }^{13,14}$. PMN, the largest pool of peripheral blood leukocytes, are the first line of defense against pathogens such as bacteria, fungi, and some viruses. They also play a crucial role in providing protection against cancer. These cells contain specific receptors on the surface of their cell membrane, which enable them to interact with the extracellular environment and with other cells. These include, inter alia, receptors for Fc fragment of immunoglobulins

\footnotetext{
${ }^{1}$ Department of Immunology, Medical University of Bialystok, ul. Waszyngtona 15A, 15-269, Bialystok, Poland. ${ }^{2}$ Department of Hematological Diagnostics, Medical University of Bialystok, ul. Waszyngtona 15A, 15-269, Bialystok, Poland. ${ }^{3}$ Regional Centre for Transfusion Medicine, Bialystok, ul. M. Skłodowskiej - Curie 23, 15-950, Bialystok, Poland. *email: wioletta.ratajczak-wrona@umb.edu.pl
} 


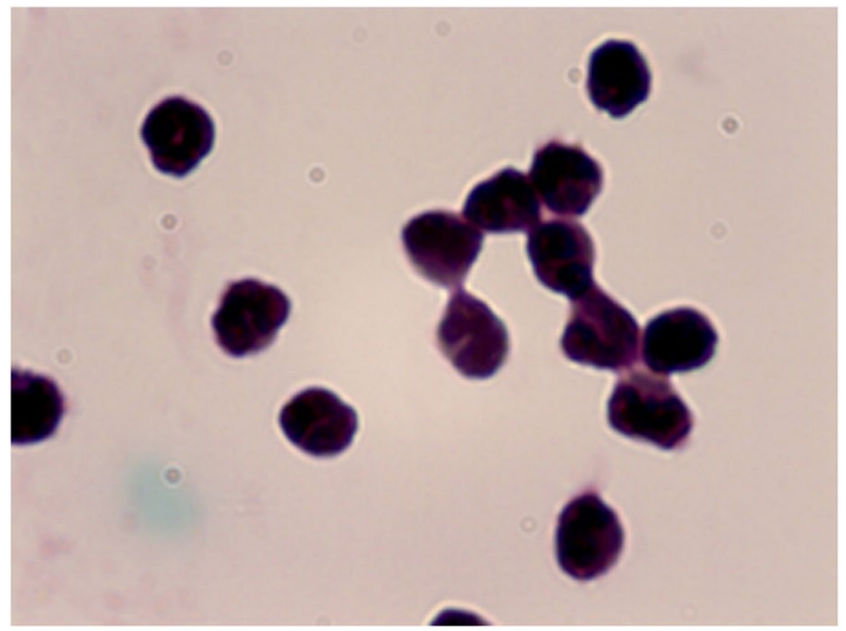

Figure 1. The $97 \%$ pure neutrophils after isolation in density centrifugation and positive selection with CD16 beads. Neutrophils were stained by May-Grünwald-Giemsa and assessed in the light microscope. Malignation $\times 100$.

(CD16), complement components (Complement receptor - CR), adhesion molecules (CD11c, CD15, CD62L), LPS (CD14), as well as receptors for hormones including estradiol (NR3). The receptors respond to the external stimuli by providing appropriate signals that further help in the activation and functioning of various intracellular transmission pathways, which include pathogen recognition, opsonization, phagocytosis, complement activation, and initiation of PMN death through apoptosis ${ }^{15-18}$.

Our previous studies have shown the influence of BPA on the mechanism of intracellular oxygen-dependent (related to nitric oxide) and oxygen-independent (related to serine protease release) killing of PMN in both women and men ${ }^{19,20}$. Moreover, the observed effects of xenoestrogen activity in these cells were dependent on the sex. Therefore, we undertook further studies in women and men to determine the influence of BPA on the expression of CD11c, CD14, CD15, CD16, and CD62L antigens on the surface of PMN, which are known to participate in the basic functions related to the diagnosis and elimination of pathogens.

Due to the fact that the mechanisms involved in EDC action are very complex and conditioned by the ability to act simultaneously on many receptors, which results in observed differential effects, it is difficult to unequivocally determine the toxicity of these compounds. EDCs show a non-monotonic dose-effect relationship, in which both very low and high doses can provide maximum response, while no effect is observed at intermediate doses. This relationship is often presented as a U-shaped curve. In the case of EDCs, a dose-effect relationship may also be presented as an inverted U-shaped curve, where intermediate doses confer the maximum effect ${ }^{21-23}$. Based on the literature data ${ }^{24-26}$, our use of high BPA concentrations $(1.5-12 \mu \mathrm{M})$ is intended to implement modern standards for immunotoxicological studies which would further allow to determine the linear (or nonlinear) dose-effect relationship in terms of BPA effect on the expression of the molecules studied. In previous studies undertaken in our laboratory, BPA was present in $97 \%$ of the analyzed serum samples of healthy subjects, and its mean concentration was found to be $14.94 \mathrm{nM}$ in women and $17.17 \mathrm{nM}$ in men $^{19}$.

\section{Material and Methods}

Isolation and incubation of PMNs. The tested blood was obtained from 15 volunteer donors from the Regional Centre for Transfusion Medicine (Bialystok, Poland). Famales were in follicular phase of menstrual cycle. All blood donors were in age 20-25 years, do not smoke, do not alcohol consume 48 hours prior blood donation. They do not have any chronic diseases and immunological deficiencies in medical history ${ }^{19,20}$.

All donors have been informed regarding the study objectives and methodology, and have provided written consent for participation in the study.

The approval for the conductance of the study titled "Assessment of bisphenol A influence on the immunophenotype of human peripheral blood leukocytes" (Resolution no.: R-I-002/95/2018) was granted by the Bioethics Committee of the Medical University of Białystok. All of the experiments were performed in accordance with good laboratory practice.

The study material included venous blood collected with an anticoagulant (heparin, Polfa, Lodz, Poland) and without an anticoagulant for serum purpose. From each donor, $4 \mathrm{ml}$ of venous blood was drawn and overlaid on Polymorphprep $^{\text {TM }}$ (AXIS-SHIELD PoC AS, Oslo, Norway). Neutrophils were isolated by centrifuging the sample at $400 \times g$ for $30 \mathrm{~min}$ in a density gradient. Cells were counted in a Bürker chamber after staining the cell nuclei with Türk's solution. Subsequently, purity of the cell suspension was assessed by performing "thick drop" method by utilizing May-Grünwald and Giemsa stains. The samples of donor cells that demonstrated neutrophil purity of more than $85 \%$ were subjected to a subsequent stage of cell isolation. During positive separation process, we were able to effectively isolate neutrophils in accordance with the protocol recommended by Miltenyi Biotec company using MACS $^{\circledR}$ Separator and CD16 MicroBeads (catalog no. 130-045-701) (Fig. 1).

The viability of neutrophils was determined using trypan blue staining (Lachema), which does not penetrate live cells but dead cells (late apoptotic and necrotic) are permeable to the stain and appear blue. Neutrophils 
A

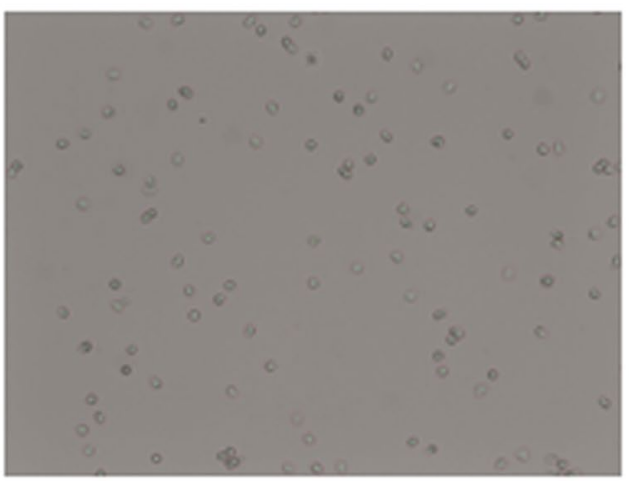

B

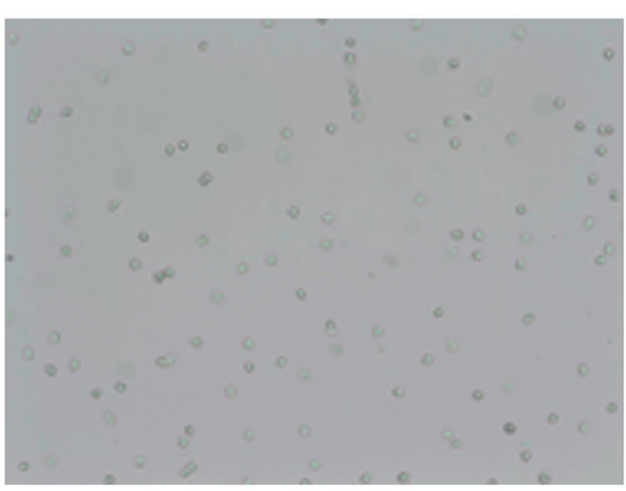

Figure 2. The $98 \%$ survival of the neutrophils stained with trypan blue. Cells were counted in the light microscope. Malignation $\times 100$. (A) cells after isolation; (B) cells affter 20 hours incubation.

stained with trypan blue were counted manually under a light microscope. Neutrophil viability was analyzed in the preparations developed directly after isolation, as well as in those obtained after 20 hours of incubation (Fig. 2).

The isolated neutrophils were cultured on the HBSS medium (Invitrogen, Carlsbad, CA), which was enriched with donor's serum and antibiotics (penicillin and streptomycin (Polfa Trachomin SA, Warsaw, Poland)). The cells were incubated for 20 hours in sterile plates at $37^{\circ} \mathrm{C}$ in $5 \% \mathrm{CO}_{2}$ (Nuaire ${ }^{\mathrm{TM}}$ US Autoflow, Plymouth, MN). Neutrophils can survive in the peripheral blood for approx. 8 hours, and then move to the tissues where they can sustain for 2 to 3 days. Recent studies have demonstrated that their survival period may be much longer-even up to about 90 hours $^{27}$. Based on these data, as well as considering the outcomes of earlier research on bisphenol A, we undertook the following study, wherein we exposed neutrophils to bisphenol A (at concentrations $12 \mu \mathrm{M}$, $6 \mu \mathrm{M}, 3 \mu \mathrm{M}, 1.5 \mu \mathrm{M}$, and $16 \mathrm{nM}$ ) or LPS (at concentration $10 \mu \mathrm{g} / \mathrm{ml}$ ) for 20 hours $^{19,20}$.

Bisphenol A (catalog no. 42088-100 MG, Sigma-Aldrich) employed in this study is $99 \%$ pure and is provided with Certificate of Analysis: Certified Reference Material. Lipopolysaccharides (LPS) used for the study (catalog no. L3129, Sigma-Aldrich) were obtained from Escherichia coli O127: B8 and purified by phenol extraction to $97 \%$ purity. The LPS fraction thus extracted contains $<3 \%$ of other proteins, this compound has also been provided with the Certificate of Analysis.

Flow cytometry analysis. To $50 \mu \mathrm{l}$ of the cells suspended in PBS, $20 \mu \mathrm{l}$ of each of the following monoclonal antibodies was added: anti-CD11c, anti-CD14, anti-CD15, anti-CD16, anti-CD62L, and anti-CD284 (TLR4). After 30 minutes of incubation in the dark, the samples were rinsed with PBS by centrifuging for 5 minutes. The results were analyzed for 30 minutes on a flow cytometer (Canto II, Becton Dickinson) using FACSDiva software.

Statistics. Statistical analysis was done using Statsoft Statistica version 13.3. Data was presented in terms of mean \pm S.E or mean \pm SD. The normal distribution of data was tested by the Kolmogorov-Smirnov test. The CD data were compared with the Mann-Whitney $U$ test. Differences were considered statistically significant when the $P<0.05$.

\section{Results}

Evaluation of CD11c, CD14, CD15, CD16, and CD62L expression in female and male neutrophils. The expression of CD11c, CD14, CD15, CD16, and CD62L cell surface antigens was demonstrated on the cell membrane of PMN in women and men (Fig. 3).

Exposure of female PMN to BPA (at concentrations of $12 \mu \mathrm{M}, 6 \mu \mathrm{M}, 3 \mu \mathrm{M}, 1.5 \mu \mathrm{M}$, or $16 \mathrm{nM}$ ) led to a decrease in the percentage of PMN expressing CD11c, CD15, and CD16 markers compared to cells not treated with xenoestrogen. On the other hand, the highest BPA concentration resulted in a higher percentage of PMN showing CD62L expression compared to non-xenoestrogen-treated cells. However, in the presence of other applied BPA concentrations $(6 \mu \mathrm{M}, 3 \mu \mathrm{M}, 1.5 \mu \mathrm{M}$, or $16 \mathrm{nM})$, no changes in the percentage of PMN expressing CD62L antigen were found (Fig. 4).

Exposing the PMN of female as well as male participants to $16 \mathrm{nM}$ BPA led to an increase in the percentage of CD14-expressed PMN compared to non-xenoestrogen-treated cells. In the presence of other applied BPA concentrations, no changes in the percentage of PMN with CD14 expression at the surface were found (Fig. 4).

Similar to the results obtained for female PMN, incubation of male cells with BPA (at all applied concentrations) showed a lower percentage of PMN expressing CD15 and CD16 markers on their surface compared to PMN incubated without xenoestrogen. The highest BPA concentration $(12 \mu \mathrm{M})$ caused a decrease in the percentage of PMN with CD11c antigen. The exposure of PMN to other BPA concentrations $(6 \mu \mathrm{M}, 3 \mu \mathrm{M}, 1.5 \mu \mathrm{M}$, or $16 \mathrm{nM}$ ) showed no changes in the percentage of PMN with CD11c antigen. No changes in the percentage of PMN with CD62L expression were observed in the presence of all BPA concentrations (Fig. 4).

Stimulation of PMN with LPS in women and men caused an increase in the percentage of PMN expressing CD11c, CD14, CD15, CD16, and CD62L antigens compared to the cells not stimulated by LPS and not exposed to BPA (Fig. 4). 
women
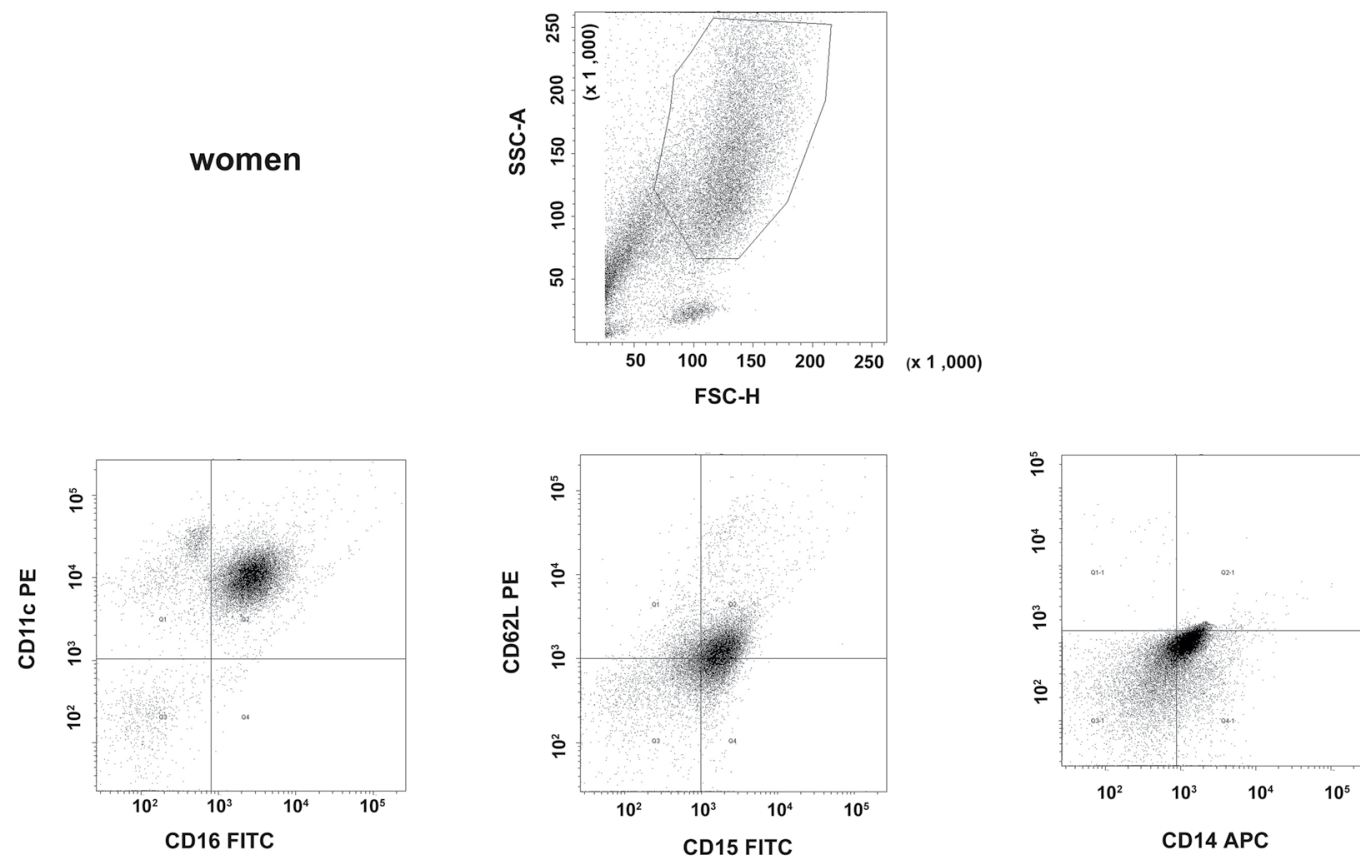

men
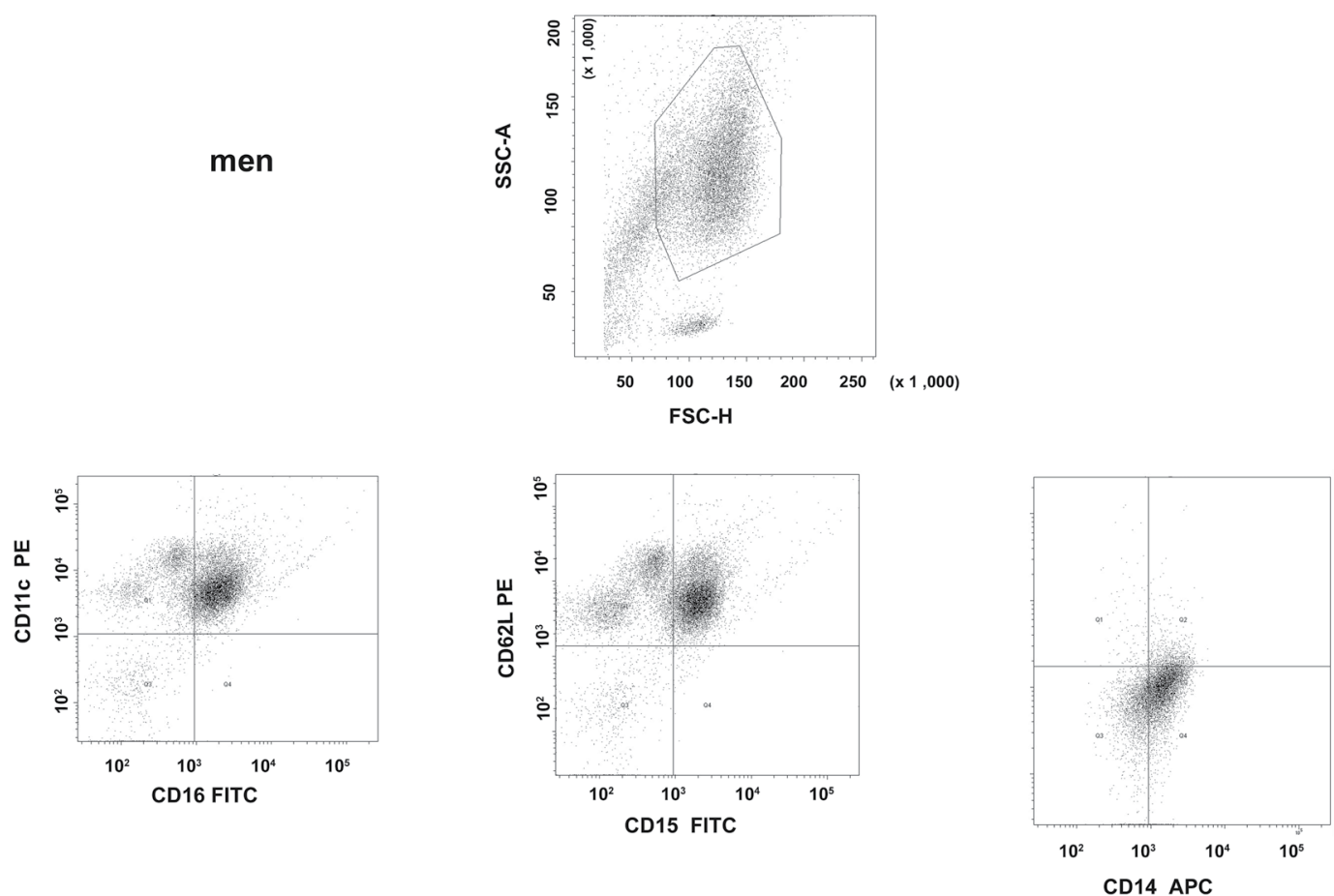

Figure 3. Representative FCAS plots demonstrating of CD antigens expression on the PMN.

A lower percentage of PMN with CD11c and CD15 expression was found in female PMN following exposure to LPS and $12 \mu \mathrm{M}$ concentration of BPA compared to the cells stimulated by LPS. However, no changes were observed in the percentage of PMN expressing these markers in the presence of LPS and other applied BPA concentrations $(6 \mu \mathrm{M}, 3 \mu \mathrm{M}, 1.5 \mu \mathrm{M}$, or $16 \mathrm{nM})$ (Fig. 4 ).

In contrast to the results obtained in females for PMN, incubation of male cells with BPA at 12,6 , or $3 \mu \mathrm{M}$ concentrations led to a decrease in the percentage of PMN with CD11c expression compared to LPS-stimulated cells. Moreover, similarly as in women, a reduced percentage of PMN with CD15 expression was observed in the presence of LPS and the highest BPA concentration used (Fig. 4).

When female and male PMN were exposed simultaneously to both LPS and xenoestrogen BPA $(12 \mu \mathrm{M}, 6 \mu \mathrm{M}$, $3 \mu \mathrm{M}, 1.5 \mu \mathrm{M}$, or $16 \mathrm{nM}$ ) stimulators, no changes in the percentage of PMN with CD14 expression were found compared to cells stimulated by LPS only (Fig. 4). 

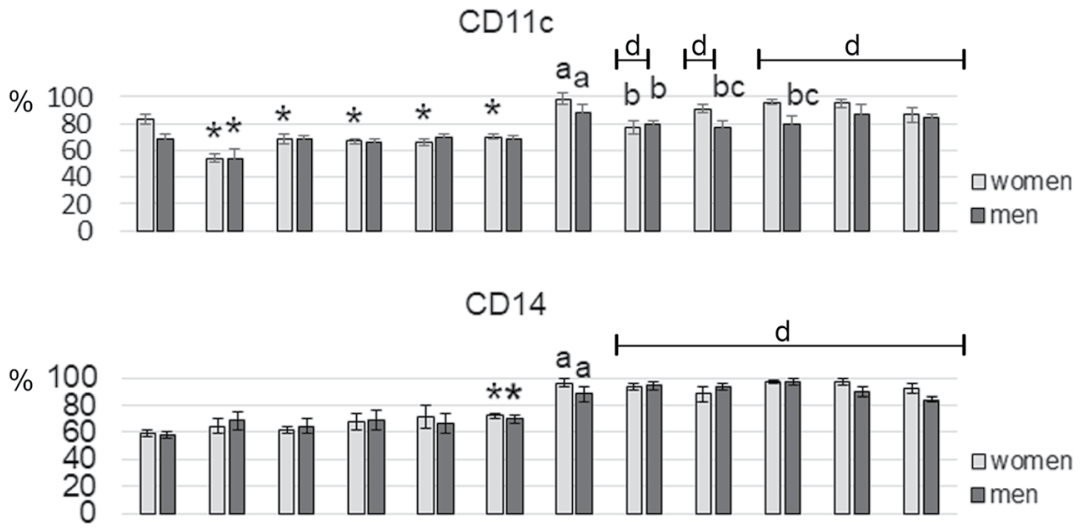

CD15
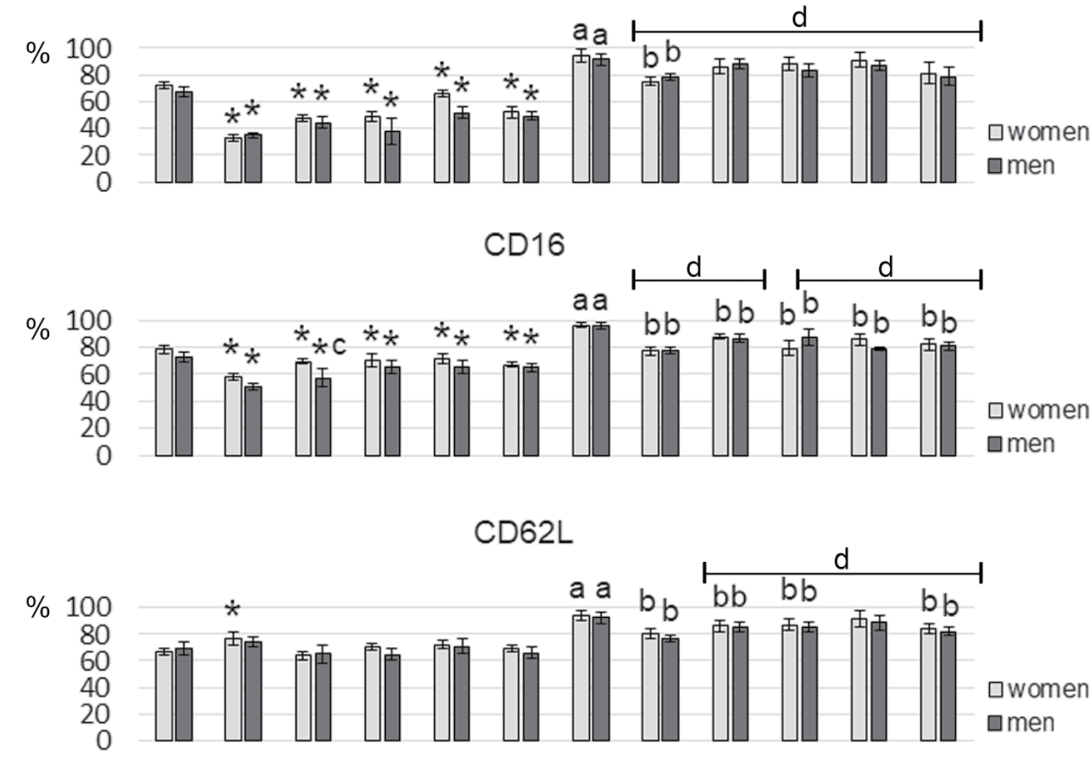

$\begin{array}{lcccccccccccc}\text { BPA } & - & 12 & 6 & 3 & 1,5 & 16 & - & 12 & 6 & 3 & 1,5 & 16 \\ & & \mu \mathrm{M} & \mu \mathrm{M} & \mu \mathrm{M} & \mu \mathrm{M} & \mathrm{nM} & & \mu \mathrm{M} & \mu \mathrm{M} & \mu \mathrm{M} & \mu \mathrm{M} & \mathrm{nM}\end{array}$

Figure 4. Alterations in CD11c, CD14, CD15, CD16 and CD62L in human PMN. PMN were treated for 20 hours with BPA $(12 \mu \mathrm{M}, 6 \mu \mathrm{M}, 3 \mu \mathrm{M}, 1.5 \mu \mathrm{M}$ or $16 \mathrm{nM})$ and/or LPS $(10 \mu \mathrm{g} / \mathrm{ml}) . \%$ - percentage share of cells with positive antigen expression; value significantly different between * - cells without and with BPA $(p<0.05)$; (a) cells incubated only with LPS and cells incubated without BPA and LPS $(p<0.05)$; (b) cells incubated only with LPS and cells simultaneously incubated with LPS and BPA $(p<0.05)$; (d) cells incubated only with BPA and cells incubated with LPS and BPA $(p<0.05)$; (c) cells collected from women and men $(p<0.05)$.

Furthermore, simultaneous stimulation of PMN of both women and men with LPS and BPA at 12, 6, and 3 $\mu \mathrm{M}$ concentrations led to a decrease in the percentage of PMN expressing CD16 and CD62L antigens compared to LPS-stimulated cells only. Moreover, when LPS and BPA were used at $1.5 \mu \mathrm{M}$ concentration, a decrease in the percentage of CD16+ cells was observed in both sexes (Fig. 4).

In female and male neutrophils, a reduction in the percentage of neutrophils with CD16 and CD62L expression was observed after treatment with LPS and BPA $(16 \mathrm{nM})$ as compared to the cells only stimulated with LPS (Fig. 4).

Simultaneous use of LPS and BPA (at all concentrations) led to a higher percentage of PMN with CD14 and CD15 expression in women and men compared to the cells exposed to BPA only. In addition, an increase in the percentage of PMN with CD62L expression was also observed in the cells of both sexes exposed to LPS and BPA $(6 \mu \mathrm{M}, 3 \mu \mathrm{M}, 1.5 \mu \mathrm{M}$, or $16 \mathrm{nM})$ (Fig. 4$)$.

Stimulation of the cells of both sexes with LPS and BPA (at all concentrations) led to an increase in the proportion of PMN with CD11c antigen expression, except for male cells exposed to LPS and $6 \mu \mathrm{M}$ concentration of BPA, compared to cells treated with BPA only (Fig. 4). 
In addition, incubation of PMN of both sexes with LPS and BPA (at all concentrations) led to an increase in the proportion of PMN with CD16 antigen expression, except for female cells exposed to LPS and $3 \mu \mathrm{M}$ BPA, compared to the cells treated with BPA only (Fig. 4).

The analysis of the results, based on the sex of the patient, did not show any difference in the expression of CD11c, CD14, CD15, CD16, and CD62L antigens on the surface of PMN (not stimulated with LPS and not exposed to BPA, exposed only to BPA, or stimulated only with LPS) between women and men. On the other hand, a lower percentage of PMN with CD11c expression in the presence of LPS and BPA (at the concentrations of 6 and $3 \mu \mathrm{M})$ was found in men compared to women. No changes were observed in the percentage of PMN expressing CD14, CD15, CD16, and CD62L antigens between women and men (Fig. 4).

Considering the effect of the lowest concentration of bisphenol A on CD14 expression of neutrophils, we also conducted a study to assess its impact on TLR4 expression. Incubation of neutrophils of both sexes with BPA $(16 \mathrm{nM})$ resulted in an increased percentage of neutrophils with TLR4 receptor expression as compared to the cells not exposed to BPA (Fig. 5, Table 1). Stimulation with LPS of cells obtained from both sexes resulted in an elevated percentage of neutrophils with TLR4 receptor expression as compared to the non-stimulated cells with LPS (Fig. 5, Table 1). No changes were observed in the percentage of PMN expressing CD284 antigens between women and men.

\section{Discussion}

Functional disorders of phagocytes often lead to recurrent infections, most frequent among them being purulent and fungal respiratory tract infections, as well as diseases related to subcutaneous tissue, skin, mucous membranes, and deep organ abscesses ${ }^{28,29}$.

The results of this study indicate that BPA acts by inducing changes in the expression of differentiation antigens like CD11c/CD18, CD14, CD15, CD16, and CD62 on the surface of PMN and subsequently changing the immunophenotype of human PMN in both women and men. Moreover, the observed changes in the PMN antigens were not found to be sex-specific.

The influence of BPA on the phenotype of nonspecific response cells, including monocytes, was also studied by Zbucka-Kretowska et al. They demonstrated that the culturing of human monocytes with BPA led to an increase in the percentage of classical subpopulations (CD14++ CD16-) of monocytes, without significantly affecting the percentage of nonclassical subpopulations (CD14++ CD16+ and CD14+CD16++) of monocytes ${ }^{30}$.

Our own study demonstrated that BPA leads to a decrease in the percentage of PMN with CD11c expression in both women and men, which confirms the significant influence of this xenoestrogen on this glycoprotein. The demonstrated changes in the expression, and thus binding, of this receptor for fibrinogen and C4 complement component on the examined cells may lead to abnormal adhesion and phagocytosis of iC $3 \mathrm{~b}$-coated molecules, as well as may induce phagocytosis without the participation of complement components in subjects exposed to this compound ${ }^{31,32}$.

In the present study, a trend similar to CD11c glycoprotein expression was observed for changes in the percentage of PMN with CD16 antigen expression. The decreased receptor expression for Fc Ig fragment on BPA-treated PMN may consequently lead to impaired phagocytosis induction as well as cell activation, inter alia, to antibody-dependent cellular cytotoxicity (ADCC). Moreover, alteration in the expression of CD16 on PMN may contribute to the dysfunction of these cells in the regulation of immune response, antigen presentation, as well in the secretion of inflammatory reaction mediators such as IL-1, IL-6, and TNF- $\alpha$ after binding to immune complexes $^{33-36}$. The results of our study with regard to changes in the CD16 antigen expression are consistent with those reported by earlier studies. A decrease in CD16 expression on Natural killer (NK) cells due to the activity of endocrine-disrupting compounds as well as deterioration in the ability of PMN to phagocytose cells was observed under the influence of $\mathrm{BPA}^{37-40}$.

In addition, the study of PMN of both sexes exposed to different concentrations of BPA also showed a decrease in the percentage of PMN with CD15 antigen expression (stage-specific embryonic antigen 1), which may ultimately lead to abnormalities in various functions of these cells, including adhesion, phagocytosis, oxygen explosion, and degranulation ${ }^{41}$. Due to the wide involvement of CD15 molecule in the immune response, it seems particularly worrying that we observed changes in the expression of this molecule in the presence of the lowest xenoestrogen concentration, which corresponds to the average concentration of BPA determined in the human bloodstream $(16 \mathrm{nM})^{19}$.

Moreover, overexpression of CD14, observed in this study, following exposure to the lowest concentration of bisphenol A $(16 \mathrm{nM})$ may result in an elevated risk of systemic inflammation during infection with Gram-negative bacteria in individuals exposed to this xenoestrogen. There is evidence that the excessive expression of CD14 in transgenic mice increases their susceptibility to endotoxic shock and an increase in SCD14 in humans is related to increased mortality due to shock caused by G- and G+ bacteria ${ }^{42}$.

In the light of the available data, which shows that the key step in the production of inflammatory mediators is the activation of the "endotoxin receptor complex" (CD14 and MD2 molecules and Toll 4 receptor), the ability of BPA to activate the TRL4 receptor, as demonstrated by us as well as other authors, seems to be of particular importance ${ }^{43}$. The interactions of BPA with CD14 and TRL4 may lead to an increased expression of proinflammatory genes and thereby cytokine synthesis ${ }^{44}$. On the other hand, the interaction of BPA with CD14 may contribute to the disturbed internalization of TLR4 dependent on CD14 protein $^{45}$.

In the presented study, observed increase in the percentage of PMN in women with CD62L (L-selectin) expression in the presence of the highest concentration of BPA, which may lead to increased interaction of these cells with the vascular endothelium, seems surprising ${ }^{46,47}$. Different results were presented by Török et al., who showed that the expression of this molecule on the PMN surface decreased significantly under the influence of even a slight stimulation, whereas no change in the expression was noted on the monocyte surface ${ }^{48}$. 


\section{women}
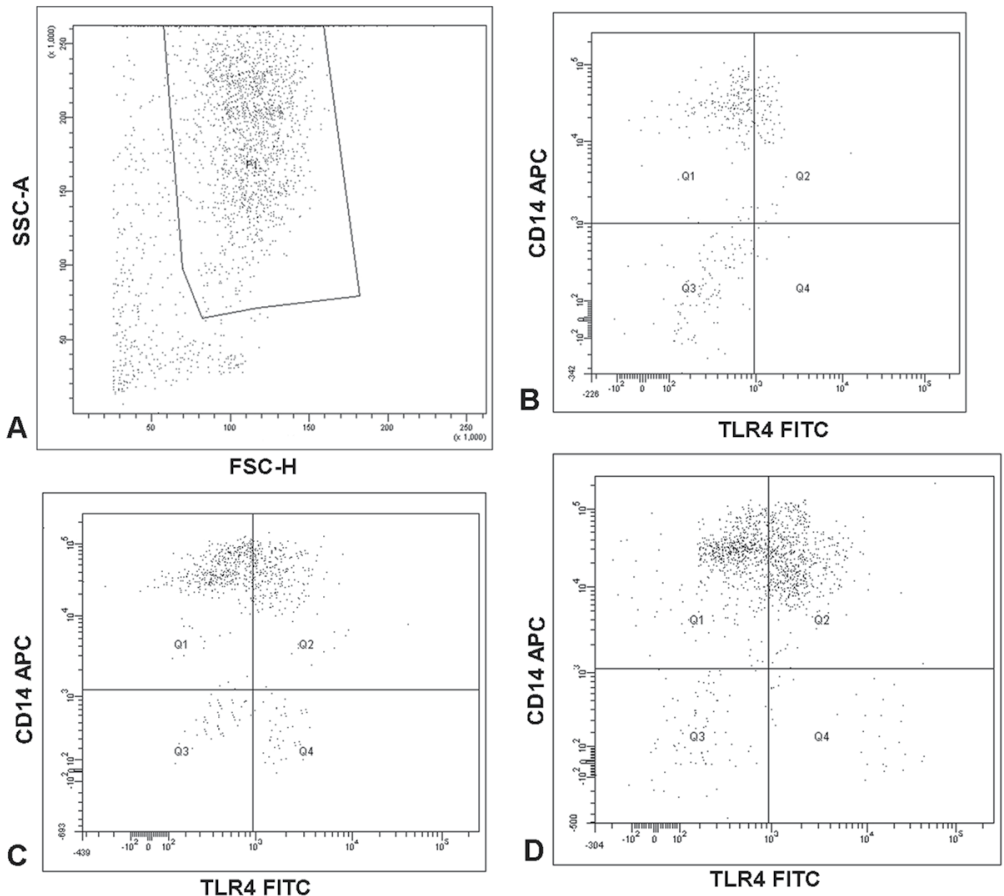

men
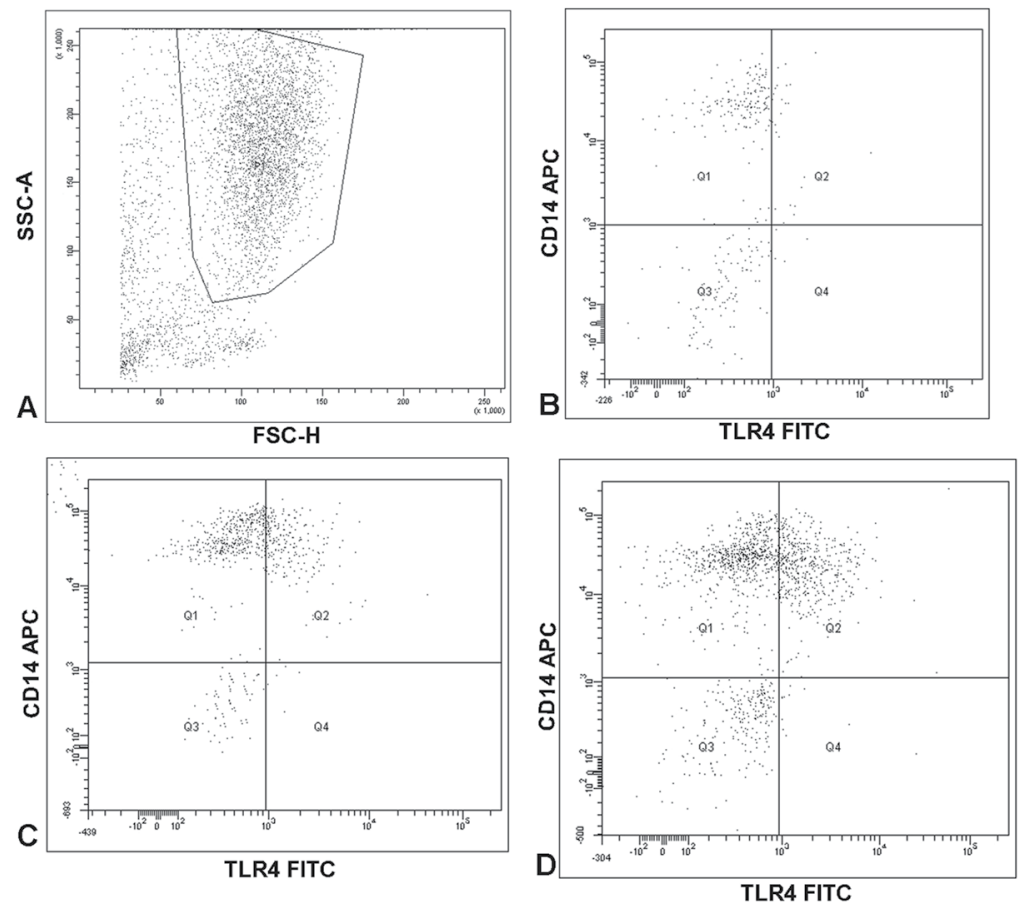

Figure 5. Representative FCAS plots demonstrating of CD antigens (CD14 and CD284 (TLR4)) expression on the PMN: (A) PMN; (B) PMN without BPA and LPS; (C) cells incubated only with BPA (16 nM); (D) cells incubated only with LPS.

Some studies have reported that PMN of people chronically exposed to endocrine-disrupting compounds, such as dichlorodiphenyltrichloroethane (DDT), show a decreased ability to chemotaxis, adhesion, phagocytosis, and oxygen-dependent killing. Moreover, it was observed that the dysfunction of these cells was associated with an increase in the incidence of infectious diseases, particularly upper respiratory tract infections, in this group of people ${ }^{49}$.

The results of our study showed that stimulation of PMN of both sexes with endotoxin (the main component of the outer membrane of Gram-negative bacteria) leads to an increased percentage of the cells expressing CD11c, 


\begin{tabular}{|l|l|l|}
\hline \multirow{2}{*}{} & \multicolumn{2}{|l|}{ TLR4 (CD284) } \\
\cline { 2 - 3 } & women Mean \pm SD & men Mean \pm SD \\
\hline PMN & $6.8 \pm 1.92$ & $5.9 \pm 1.97$ \\
\hline PMN + BPA $(16 \mathrm{nM})$ & $16.75^{*} \pm 4.33$ & $14.1^{*} \pm 4.21$ \\
\hline PMN + LPS & $31.1^{\mathrm{a}} \pm 7.23$ & $26.1^{\mathrm{a}} \pm 7.52$ \\
\hline
\end{tabular}

Table 1. Alterations in TLR4 (CD284) in human PMN. PMN were treated for 20 hours with BPA (16nM) or LPS $(10 \mu \mathrm{g} / \mathrm{ml})$. Value significantly different between * - cells without and with BPA $(p<0.05) ;{ }^{\text {a }}-$ cells incubated only with LPS and cells incubated without BPA and LPS $(p<0.05)$.

CD14, CD15, CD16, and CD62L antigens, which suggests a proper development of inflammatory response to bacterial toxin. Similar observations were made by Rodeberg et al., who observed an increase in CD14 expression on PMN stimulated by LPS ${ }^{50}$. Different results were reported by Vega et al. with regard to CD62L marker ${ }^{51}$. They did not observe any changes in the expression of this selectin on PMN as a result of LPS stimulation. Kishimoto et al., however, demonstrated reduced CD62L expression on PMN following stimulation with the endotoxin ${ }^{52}$.

In order to evaluate the potential influence of BPA on the inflammatory process, PMN of women and men were concurrently stimulated with LPS and xenoestrogen. The observed decrease in the percentage of PMN expressing CD11c, CD16, and CD62L antigens in both sexes suggests that xenoestrogen may prevent rapid removal of the pathogen factor and consequently lead to the development of an inflammatory process. This etiology seems to be dangerous in pregnant women, who are particularly exposed to Gram-negative bacterial infections ${ }^{53,54}$. BPA alone can lead to a number of adverse effects in the offspring, including carbohydrate metabolism disorders ${ }^{55}$, fertility disorders ${ }^{56}$, and nervous system abnormalities ${ }^{57}$.

However, the study conducted in our laboratory did not show any influence of BPA on the percentage of PMN with CD14 expression after stimulation with LPS. This situation may be probably caused by higher affinity of bacterial endotoxin to TLR receptors compared to BPA ${ }^{58,59}$. LPS binds to a protein molecule (LPS binding protein) present in the serum, which in turn transports and transfers it to CD14. This receptor is anchored to the membrane by a glycosylphosphatidylinositol connector and is not capable of transmitting a signal by itself; only after the formation of a complex with TLR4, the cell can be activated ${ }^{60,61}$. On the other hand, the question arises as to whether we would also observe changes in the percentage of PMN with CD14 expression if these cells were exposed simultaneously to BPA and another component of the bacterial cell wall, which is lipoteichoic acid (LTA) from Gram-positive bacteria. There are data reporting that LTA induces the activation of PMN with CD14 expression, independent of binding with the Toll-like receptors, TLR2 or TLR ${ }^{62}$.

In conclusion, it has already been established that BPA at a concentration corresponding to the serum level of this compound in healthy subjects as well as at higher doses affects the immunophenotype of PMN, which may subsequently lead to immunodeficiency disorders associated with dysfunction of these cells in subjects exposed to this compound. Moreover, the observed effects of xenoestrogen on the expression of CD11c, CD14, CD15, CD16, and CD62L differentiation markers on these cells are sex-independent.

The effects of BPA activity on the reproductive system and neonatal development have been widely recognized. However, there is little information with regard to its effects on the cells of the immune system, especially PMN. A thorough understanding of the mechanism of BPA action on PMN together with a description of the role of estrogenic receptors in these cells will allow for a realistic assessment of the risks resulting from wide exposure to this xenoestrogen. Therefore, further research is needed to determine the possible effects of BPA on the functioning of important immune cells, such as PMN.

Ethical approval and consent to participate. The Ethics Committee of the Medical University of Bialystok (R-I-002/95/2018) approved this study. Informed consent was obtained from all participants prior to blood donations. All of the experiments were performed in accordance with good laboratory practice.

\section{Data availability}

The datasets used and/or analyzed during the current study are availablefrom the corresponding author on reasonable request.

Received: 2 December 2019; Accepted: 3 February 2020;

Published online: 20 February 2020

\section{References}

1. Rubin, B. S. Bisphenol A: an endocrine disruptor with widespread exposure and multiple effects. J. Steroid Biochem. Mol. Biol. 127, 27-34, https://doi.org/10.1016/j.jsbmb.2011.05.002 (2011).

2. Fenichel, P., Chevalier, N. \& Brucker-Davis, F. Bisphenol A: an endocrine and metabolic disruptor. Ann. Endocrinol. 74, 211-220, https://doi.org/10.1016/j.ando.2013.04.002 (2013).

3. Rochester, J. R. Bisphenol A and human health: a review of the literature. Reprod. Toxicol. 42, 132-155, https://doi.org/10.1016/j. reprotox.2013.08.008 (2013).

4. Shelnutta, S., Kind, J. \& Allaben, W. Bisphenol A: Update on newly developed data and how they address NTP's 2008 finding of "Some Concern". Food Chem. Toxicol. 57, 284-295, https://doi.org/10.1016/j.fct.2013.03.027 (2013).

5. Gatimel, N. et al. Bisphenol A in culture media and plastic consumables used for ART. Hum. Reprod. 31, 1436-1444, https://doi. org/10.1093/humrep/dew116 (2016).

6. Carlsson, A., Sørensen, K., Andersson, A. M., Frederiksen, H. \& Juul, A. Bisphenol A, phthalate metabolites and glucose homeostasis in healthy normal-weight children. Endocr. Connect. 7, 232-238, https://doi.org/10.1530/EC-17-0344 (2018).

7. Komarowska, M. et al. Serum bisphenol A level in boys with cryptorchidism: A step to male infertility? Int. J. Endocrinol. 973154, 1-8, https://doi.org/10.1155/2015/973154 (2015). 
8. Vandenberg, L. N., Hunt, P. A., Myers, J. P. \& Vom Saal, F. S. Human exposures to bisphenol A: mismatches between data and assumptions. Rev. Env. Health. 28, 37-58, https://doi.org/10.1515/reveh-2012-0034 (2013).

9. Kang, J. H., Kondo, F. \& Katayama, Y. Human exposure to bisphenol A. Toxicology. 226, 79-89, https://doi.org/10.1016/j. tox.2006.06.009 (2006)

10. Carlisle, J. et al. Toxicological profile for bishenol A. Integrated Risk Assessment Branch Office of Environmental Health Hazard Assessment California Environmental Protection Agency 2009;1-44. http://www.opc.ca.gov/webmaster/ftp/project_pages/ MarineDebris_OEHHA_ToxProfiles/Bisphenol\%20A\%20Final.pdf(Access 6.08.2019).

11. Yoshino, S. et al. Prenatal exposure to bisphenol A up-regulates immune responses, including T helper 1 and T helper 2 responses, in mice. Immunology. 112, 489-495, https://doi.org/10.1111/j.1365-2567.2004.01900.x (2004).

12. Xu, J., Huang, G. \& Guo, T. L. Developmental Bisphenol A exposure modulates immune-related diseases. Toxics. 4, E23, https://doi. org/10.3390/toxics4040023 (2016).

13. Santovito, A., Cannarsa, E., Schleicherova, D. \& Cervella, P. Clastogenic effects of bisphenol A on human cultured lymphocytes. Hum. Exp. Toxicol. 37, 69-77, https://doi.org/10.1177/0960327117693069 (2018).

14. Zhu, J. et al. MAPK and NF- $\mathrm{KB}$ pathways are involved in bisphenol A-induced TNF- $\alpha$ and IL-6 production in BV2 microglial cells. Inflammation. 38, 637-648, https://doi.org/10.1007/s10753-014-9971-5 (2015).

15. Mócsai, A. Diverse novel functions of neutrophils in immunity, inflammation, and beyond. JEM. 210, 1283-1299, https://doi. org/10.1084/jem.20122220 (2013).

16. Nathan, C. Neutrophils and immunity: challenges and opportunities. Nat. Rev. Immunol. 6, 173-182, https://doi.org/10.1038/ nri1785 (2006)

17. Sagiv, J. Y. et al. Phenotypic diversity and plasticity in circulating neutrophil subpopulations in cancer. Cell Rep. 10, 562-573, https:// doi.org/10.1016/j.celrep.2014.12.039 (2015)

18. Silvestre-Roig, C., Hidalgo, A. \& Soehnlein, O. Neutrophil heterogeneity: implications for homeostasis and pathogenesis. Blood. 127, 2173-2181, https://doi.org/10.1182/blood-2016-01-688887 (2016).

19. Ratajczak-Wrona, W. et al. Expression of serine proteases in neutrophils from women and men: Regulation by endocrine disruptor bisphenol A. Env. Toxicol. Pharmacol. 71, 103212, https://doi.org/10.1016/j.etap.2019.103212 (2019).

20. Ratajczak-Wrona, W., Nowak, K., Garley, M., Tynecka, M. \& Jablonska, E. Sex-specific differences in the regulation of inducible nitric oxide synthase by bisphenol A in neutrophils. Hum. Exp. Toxicol. 38, 239-246, https://doi.org/10.1016/j.etap.2019.103212 (2019).

21. Xu, Z., Liu, J., Wu, X., Huang, B. \& Pan, X. Nonmonotonic responses to low doses of xenoestrogens: A review. Env. Res. 155, 199-207, https://doi.org/10.1016/j.envres.2017.02.018 (2017).

22. Nowak, K., Jabłońska, E. \& Ratajczak-Wrona, W. Immunomodulatory effects of synthetic endocrine disrupting chemicals on the development and functions of human immune cells. Env. Int. 125, 350-364, https://doi.org/10.1016/j.envint.2019.01.078 (2019).

23. Vandenberg, L. N. et al. Hormones and endocrine-disrupting chemicals: low-dose effects and nonmonotonic dose response. Endocr. Rev. 33, 378-455, https://doi.org/10.1210/er.2011-1050 (2012).

24. George, V. C. \& Rupasinghe, H. P. V. DNA damaging and apoptotic potentials of Bisphenol A and Bisphenol S in human bronchial epithelial cells. Env. Toxicol. Pharmacol. 60, 52-57, https://doi.org/10.1016/j.etap.2018.04.009 (2018).

25. Zhang, Y. et al. Bisphenol A affects cell viability involved in autophagy and apoptosis in goat testis sertoli cell. Env. Toxicol. Pharmacol. 55, 137-147, https://doi.org/10.1016/j.etap.2017.07.014 (2017).

26. Bujnakova Mlynarcikova, A. \& Scsukova, S. Simultaneous effects of endocrine disruptor bisphenol A and flavonoid fisetin on progesterone production by granulosa cells. Env. Toxicol. Pharmacol. 59, 66-73, https://doi.org/10.1016/j.etap.2018.03.001 (2018).

27. Pillay, J. et al. In vivo labeling with $2 \mathrm{H} 2 \mathrm{O}$ reveals a human eutrophil lifespan of 5.4 days. Blood. 116, 625-627, https://doi. org/10.1182/blood-2010-01-259028 (2010).

28. Rashmi, S. M., Alka, D. K. \& Ramakant, S. N. Neutrophils health disease: An. Overv. JOMFP 10, 3-8, https://doi.org/10.4103/0973029X.37740 (2006).

29. Amulic, B., Cazalet, C., Hayes, G. L., Metzler, K. D. \& Zychlinsky, A. Neutrophil function: from mechanisms to disease. Annu. Rev. Immunol. 30, 459-489, https://doi.org/10.1146/annurev-immunol-020711-074942 (2012).

30. Zbucka-Kretowska, M., Poplawska, I., Kretowska, A., Moniuszko, M. \& Grubczak, K. Short-term in vitro effects of bisphenol A activity on phenotype and function of peripheral blood immune system cells. Food Chem. Toxicol. 110, 262-273, https://doi. org/10.1016/j.fct.2017.10.034 (2017).

31. Mann, B. S. \& Chung, K. F. Blood neutrophil activation markers in severe asthma: lack of inhibition by prednisolone therapy. Respir. Res. 7, 59, https://doi.org/10.1186/1465-9921-7-59 (2006).

32. Sadhu, C. et al. CD11c/CD18: novel ligands and a role in delayed-type hypersensitivity. J. Leukoc. Biol. 81, 1395-1403, https://doi. org/10.1189/jlb.1106680 (2007).

33. Borregaard, N. Neutrophils, from marrow to microbes. Immunity. 33, 657-670, https://doi.org/10.1016/j.immuni.2010.11.011 (2010).

34. Flannagan, R. S., Jaumouillé, V. \& Grinstein, S. The cell biology of phagocytosis. Annu. Rev. Pathol. 7, 61-98, https://doi.org/10.1146/ annurev-pathol-011811-132445 (2012).

35. Hazlett, L. \& Wu, M. Defensins in innate immunity. Cell Tissue Res. 343, 175-188, https://doi.org/10.1007/s00441-010-1022-4 (2011).

36. Nordenfelt, P. \& Tapper, H. Phagosome dynamics during phagocytosis by neutrophils. J. Leukoc. Biol. 90, 271-284, https://doi. org/10.1189/jlb.0810457 (2011).

37. Sugita-Konishi, Y. et al. Effect of Bisphenol A on non-specific immunodefenses against non-pathogenic Escherichia coli. Toxicol. Lett. 136, 217-227, https://doi.org/10.1016/s0378-4274(02)00388-0 (2003).

38. Dudimah, F. D., Odman-Ghazi, S. O., Hatcher, F. \& Whalen, M. M. Effect of tributyltin (TBT) on ATP levels in human natural killer (NK) cells: relationship to TBT-induced decreases in NK function. J. Appl. Toxicol. 27, 86-94, https://doi.org/10.1002/jat.1202 (2007).

39. Thomas, L. D., Shah, H., Green, S. A., Bankhurst, A. D. \& Whalen, M. M. Tributyltin exposure causes decreased granzyme B and perforin levels in human natural killer cells. Toxicology. 200, 221-233, https://doi.org/10.1016/j.tox.2004.04.002 (2004).

40. Whalen, M. M., Ghazi, S., Loganathan, B. G. \& Hatcher, F. Expression of CD16, CD18 and CD56 in tributyltin-exposed human natural killer cells. Chem. Biol. Interact. 139, 159-176, https://doi.org/10.1016/s0009-2797(01)00297-6 (2002).

41. Stocks, S. C., Albrechtsen, M. \& Kerr, M. A. Expression of the CD15 differentiation antigen (3-fucosyl-N-acetyl-lactosamine, LeX) on putative neutrophil adhesion molecules CR3 and NCA-160. Biochem. J. 268, 275-280, https://doi.org/10.1042/bj2680275 (1990).

42. Lin, M. T. \& Albertson, T. E. Genomic polymorphisms in sepsis. Crit. Care Med. 32, 569-579, https://doi.org/10.1097/01. CCM.0000110878.49476.42 (2004).

43. Liao, S. L. et al. Prenatal exposure to bisphenol-A is associated with Toll-like receptor-induced cytokine suppression in neonates. Pediatr. Res. 79, 438-444, https://doi.org/10.1038/pr.2015.234 (2016).

44. Wang, J. E. et al. Peptidoglycan of Staphylococcus aureus causes inflammation and organ injury in the rat. Crit. Care Med. 32, 546-552, https://doi.org/10.1097/01.CCM.0000109775.22138.8F (2004).

45. Zanoni, I. et al. CD14 controls the LPS-induced endocytosis of Toll-like receptor 4. Cell 147, 868-880, https://doi.org/10.1016/j. cell.2011.09.051 (2011) 
46. Trevani, A. S. et al. Bacterial DNA activates human neutrophils by a CpG-independent pathway. Eur. J. Immunol. 33, 3164-3174, https://doi.org/10.1002/eji.200324334 (2003).

47. Tedder, T. F., Steeber, D. A., Chen, A. \& Engel, P. The selectins: vascular adhesion molecules. FASEB J. 9, 866-873, https://doi. org/10.1096/fasebj.9.10.7542213 (1995).

48. Török, C., Lundahl, J., Hed, J. \& Lagercrantz, H. Diversity in regulation of adhesion molecules (Mac-1 and L-selectin) in monocytes and neutrophils from neonates and adults. Arch. Dis. Child. 68, 561-565, https://doi.org/10.1136/adc.68.5_spec_no.561 (1993).

49. Hermanowicz, A., Nawarska, Z., Borys, D. \& Maślankiewicz, A. The neutrophil function and infectious diseases in workers occupationally exposed to organochloride insecticides. Int. Arch. Occup. Env. Health. 50, 329-340, https://doi.org/10.1007/ bf00377829 (1982).

50. Rodeberg, D. A., Morris, R. E. \& Babcock, G. F. Azurophilic granules of human neutrophils contain CD14. Infect. Immun. 65, 4747-4753 (1997).

51. Vega, A., El Bekay, R., Chacón, P., Ventura, I. \& Monteseirín, J. Angiotensin II induces CD62L shedding in human neutrophils. Atherosclerosis. 209, 344-351, https://doi.org/10.1016/j.atherosclerosis.2009.09.067 (2010).

52. Kishimoto, T. K., Jutila, M. A., Berg, E. L. \& Butcher, E. C. Neutrophil Mac-1 and MEL-14 adhesion proteins inversely regulated by chemotactic factors. Science. 245, 1238-1241, https://doi.org/10.1126/science.2551036 (1989).

53. Taylor, E. L., Megson, I. L., Haslett, C. \& Rossi, A. G. Nitric oxide: a key regulator of myeloid inflammatory cell apoptosis. Cell Death Differ. 10, 418-430, https://doi.org/10.1038/sj.cdd.4401152 (2003).

54. Stenqvist, K. et al. Virulence factors of Escherichia coli in urinary isolates from pregnant women. J. Infect. Dis. 156, 870-877, https:// doi.org/10.1093/infdis/156.6.870 (1987).

55. Watt, S. et al. Escherichia coli strains from pregnant women and neonates: intraspecies genetic distribution and prevalence of virulence factors. J. Clin. Microbiol. 41, 1929-1935, https://doi.org/10.1128/jcm.41.5.1929-1935.2003 (2003).

56. Alonso-Magdalena, P. et al. Bisphenol A exposure during pregnancy disrupts glucose homeostasis in mothers and adult male offspring. Env. Health Perspect. 118, 1243-1250, https://doi.org/10.1289/ehp.1001993 (2010).

57. Salian, S., Doshi, T. \& Vanage, G. Perinatal exposure of rats to Bisphenol A affects the fertility of male offspring. Life Sci. 85, 742-752, https://doi.org/10.1016/j.lfs.2009.10.004 (2009).

58. Guha, M. \& Mackman, N. LPS induction of gene expression in human monocytes. Cell Signal. 13, 85-94, https://doi.org/10.1016/ s0898-6568(00)00149-2 (2001).

59. Ohnishi, T., Yoshida, T., Igarashi, A., Muroi, M. \& Tanamoto, K. Effects of possible endocrine disruptors on MyD88-independent TLR4 signaling. FEMS Immunol. Med. Microbiol. 52, 293-295, https://doi.org/10.1111/j.1574-695X.2007.00355.x (2008).

60. Kawai, T. \& Akira, S. Toll-like receptors and their crosstalk with other innate receptors in infection and immunity. Immunity. 34, 637-650, https://doi.org/10.1016/j.immuni.2011.05.006 (2011).

61. Plüddemann, A., Mukhopadhyay, S. \& Gordon, S. Innate immunity to intracellular pathogens: macrophage receptors and responses to microbial entry. Immunol. Rev. 240, 11-24, https://doi.org/10.1111/j.1600-065X.2010.00989.x (2011).

62. Hattar, K. et al. Lipoteichoic acid (LTA) from Staphylococcus aureus stimulates human neutrophil cytokine release by a CD14dependent, Toll-like-receptor-independent mechanism: Autocrine role of tumor necrosis factor-[alpha] in mediating LTA-induced interleukin-8 generation. Crit. Care Med. 34, 835-841, https://doi.org/10.1097/01.CCM.0000202204.01230.44 (2006).

\section{Acknowledgements}

The authors thank Mrs Malgorzata Walko-Lachowicz for expert technical assistance. This work was funded by the Medical University of Bialystok, Poland, (Project no: N/ST/ZB/17/003/2206).

\section{Author contributions}

W.R.W. conducted the statistical analyses and wrote the manuscript with critical comments and input from E.J., M.R., K.N., M.D. and P.R.; W.R.W., M.R., K.N., P.R., M.D. and E.J. designed the research plan; W.R.W., M.R. and K.N. conducted the original study and follow-up study from which the data were generated. All authors read and approved the final manuscript.

\section{Competing interests}

The authors declare no competing interests.

\section{Additional information}

Correspondence and requests for materials should be addressed to W.R.-W.

Reprints and permissions information is available at www.nature.com/reprints.

Publisher's note Springer Nature remains neutral with regard to jurisdictional claims in published maps and institutional affiliations.

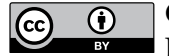

Open Access This article is licensed under a Creative Commons Attribution 4.0 International

License, which permits use, sharing, adaptation, distribution and reproduction in any medium or format, as long as you give appropriate credit to the original author(s) and the source, provide a link to the Creative Commons license, and indicate if changes were made. The images or other third party material in this article are included in the article's Creative Commons license, unless indicated otherwise in a credit line to the material. If material is not included in the article's Creative Commons license and your intended use is not permitted by statutory regulation or exceeds the permitted use, you will need to obtain permission directly from the copyright holder. To view a copy of this license, visit http://creativecommons.org/licenses/by/4.0/.

(c) The Author(s) 2020 